\title{
Light-Dependent Monoterpene Emissions from an Oak Species Native to Asia
}

\author{
Motonori OKumura, Akira Tani***, Susumu Tohno and Aya Shimomachi* \\ Graduate School of Energy Science, Kyoto University, Uji, Kyoto 611-0011, Japan \\ * School of High-Technology for Human Welfare, Tokai University, Numazu, Shizuoka 410-0295, Japan \\ ** Institute for Environmental Sciences, University of Shizuoka, Suruga-ku, Shizuoka 422-8526, Japan
}

(Received November 25, 2008)

\begin{abstract}
This is the first report of light-dependent monoterpene emissions from an oak species native to Asia. Isoprenoids emitted by Quercus phillyraeoides were measured using branch enclosure methods. Sabinene, and $\alpha$ - and $\beta$-pinenes were the major compounds accounting for more than $90 \%$ of the total monoterpene emissions. The basal emission rates of total monoterpenes on leaf area and leaf dry weight bases ranged from 0.07 to $6.30 \mathrm{nmol} \mathrm{m}^{-2} \mathrm{~s}^{-1}$ and from 0.22 to $14.3 \mu \mathrm{g}$ $\mathrm{g}^{-1} \mathrm{~h}^{-1}$, respectively. A proton transfer reaction mass spectrometry measurement revealed that the emissions depend significantly on light intensity and leaf temperature. Q. phillyraeoides may be taxonomically close to European monoterpene-emitting oaks because it is morphologically close to the oaks native to the Mediterranean area, and because the geographical features of their habitats are similar to each other.
\end{abstract}

Keywords : emission model, monoterpene, light, Japanese evergreen oak, Quercus phillyraeoides, volatile organic compounds

\section{INTRODUCTION}

Biogenic volatile organic compounds (BVOCs) emitted by higher plants include terpenoids such as isoprene and monoterpenes, oxygenated low-molecular-weight compounds such as methanol, acetone, acetaldehyde, and ethanol, and a plant hormone ethylene. The estimation of annual global emission of all BVOCs has been conducted previously (e.g., Guenther et al., 1995; IPCC, 2001), according to which the estimated values greatly exceed the annual global emission of anthropogenic non-methane VOCs. Isoprene emission is the largest component and is estimated to comprise $50 \%$ of the annual global BVOC emission (Guenther et al., 1995).

Isoprene and monoterpenes are highly reactive VOC species and produce photochemical oxidants in a series of reactions with $\mathrm{OH}$ radical and NO. These reactions play an important role in influencing atmospheric chemistry related to regional photochemical oxidant formation (Fall, 1999) and lifetime of methane (Fehsenfeld et al., 1992). Recent studies have revealed that isoprene oxidation products may significantly contribute to the formation of secondary organic aerosols (Claeys et al., 2004).

Recently, indirect carbon emission resulting from BVOC emissions has been considered to be important. For example, Geron et al. (2002) roughly estimated that the BVOC emission offset is $10 \%$ or more of net ecosystem exchange of $\mathrm{CO}_{2}$ (NEE) for a lowland tropical wet forest in Costa

Corresponding author: Akira Tani, fax: +81-54-264-5788, e-mail : atani@u-shizuoka-ken.ac.jp 


\section{OKUMURA ET AL.}

Rica. Guenther (2002) estimated that the annual global BVOC emission was 1.2 PgC.

Isoprene emission is related to light intensity and leaf temperature, but monoterpene emissions from plants with monoterpene-specific storage organs depend mainly on leaf temperature. Therefore, isoprene emission by plants can be described by leaf temperature and light intensity, and monoterpene emissions by leaf temperature, using simple algorithms developed by Guenther et al. (1993). In Europe and the United States, there have been various investigations to identify BVOC emitters and characterize their emissions. Trees in the genus Quercus have been recognized as strong isoprene emitters (Kesselmeier and Staudt, 1999). However, several Mediterranean oak species such as $Q$. ilex and $Q$. coccifera are reported to be monoterpene emitters, but have no storage organs (Kesselmeier et al., 1996). The monoterpene emissions of Q. ilex are strongly affected by light intensity and leaf temperature (Staudt and Seufert, 1995; Peñuelas and Llusià, 1999), and are successfully predicted by isoprene algorithms under steady state conditions (Ciccioli et al., 1997). On the other hand, the isoprenoid emissions by Asian plant species have been little studied (Yokouchi and Ambe, 1981; Klinger et al., 2002; Loreto et al., 2002; Tani et al., 2002). We have been conducting studies to identify isoprenoid emitters in Japan and investigate their emission characteristics (Tani and Fushimi, 2005; Okumura et al., 2008). Quercus trees occur widely in Japan and some of the deciduous species are strong isoprene emitters (Loreto, 2002; Tani and Kawawata, 2008). However, no Quercus monoterpene-emitters have so far been found in Japan or other countries in Asia. In our investigations, we have identified the native Japanese evergreen oak species, $Q$. phillyraeoides, as a monoterpene emitter. In this study, we show the monoterpene emission characteristics of $Q$. phillyraeoides as affected by leaf temperature and light intensity, and its basal emission rates.

\section{MATERIALS AND METHODS}

\section{Plant materials}

Four- to five-year-old saplings of $Q$. phillyraeoides were obtained from local nurseries in Yakushima Island, and Wakayama and Shizuoka Prefectures in Japan. The saplings were grown from seeds collected from each source habitat. There are large stands of $Q$. phillyraeoides in the three habitats. Five saplings of each habitat were prepared for the measurements. The plant heights ranged between 60 and $100 \mathrm{~cm}$. Plants were potted in 20-L pots and placed in an experimental garden of Tokai University in Shizuoka, Japan, for at least one month, before being used for experiments. Branch enclosure measurements were conducted in a laboratory for all trees from September to November, 2006. Saplings derived from Wakayama Prefecture were also used for leaf cuvette measurements.

\section{Branch enclosure method}

To measure and identify isoprenoids emitted from leaves of $Q$. phillyraeoides, single branches of $Q$. phillyraeoides trees were enclosed in a transparent PFA bag $(20 \mathrm{~L})$. The PFA bag had an inlet and a sampling port at the side opposite the inlet. Outside air was pumped through a platinum catalyst system, with the temperature maintained at $400^{\circ} \mathrm{C}$, to remove VOCs and other contaminants from the inflowing air. This purified air was then passed through a mass flow controller (SEC40, ESTEC, Japan) to keep the flow rate at $2.5 \mathrm{~L} \mathrm{~min}^{-1}$ at the inlet of the enclosure bag. A 400-W metal halide lamp (D400, Toshiba LiTec, Japan) was fixed $2 \mathrm{~m}$ above the floor of the laboratory. The photosynthetic photon flux density (PPFD) ranged between $500-800 \mu \mathrm{mol} \mathrm{m}^{-2} \mathrm{~s}^{-1}$ at the top of the branch enclosed in the bag. The leaf temperature in the bag, monitored with two Ttype fine thermocouples, ranged from 28 to $32^{\circ} \mathrm{C}$ in all the measurements. Two hours later, the inside air was collected into an adsorbent tube containing $200 \mathrm{mg}$ Tenax TA and $100 \mathrm{mg}$ Carbotrap B. The air was drawn into the adsorbent tubes from the sampling port by a pump (210 Pocket pump, SKC, USA) for $20 \mathrm{~min}$ at a flow rate of $130 \mu \mathrm{mol} \mathrm{s}^{-1}$. 


\section{Leaf cuvette method}

A portable photosynthetic measurement unit equipped with a controlled-environment broad leaf cuvette (LI6400, Li-Cor, USA) was used to investigate the effects of temperature and light intensity on isoprenoid emissions. For isoprenoid sampling, the outlet tube from the leaf cuvette was replaced by a Teflon tube. The outlet air flow was divided into two streams by a Teflon T-junction. One stream was reconnected to a built-in infrared gas analyzer (IRGA) in the cuvette and the other was used as a sampling port for isoprenoids. The inflow rate to the cuvette was $500 \mu \mathrm{mol} \mathrm{s}^{-1}$. The purified air, prepared by a platinum catalyst system, was supplied to the cuvette. The whole plant used for each measurement was placed under the metal halide lamp.

To examine the effects of light intensity on isoprenoid emissions, it was first set to $1,000 \mu \mathrm{mol}$ $\mathrm{m}^{-2} \mathrm{~s}^{-1}$ and then decreased to $500,200,50$, and $0 \mu \mathrm{mol} \mathrm{m}^{-2} \mathrm{~s}^{-1}$. Leaf temperature was kept at 25 $\pm 0.2^{\circ} \mathrm{C}$ in all the measurements. $\mathrm{CO}_{2}$ concentration in the cuvette was kept at $380 \pm 10 \mu \mathrm{L} \mathrm{L}^{-1}$. To examine the effects of leaf temperature on isoprenoid emissions and physiological parameters, the leaf temperature was first set at $25^{\circ} \mathrm{C}$ and then raised to 30,35 , and $37.5^{\circ} \mathrm{C}$. Light intensity was kept at $1,000 \pm 25 \mu \mathrm{mol} \mathrm{m}^{-2} \mathrm{~s}^{-1}$.

Isoprenoid concentrations in the cuvette were monitored with a proton transfer reaction mass spectrometer (PTR-MS) (Ionicon GmbH, Austria), and the data were obtained at $\sim 1$-min intervals. The gas from the cuvette was successively collected in three adsorbent tubes after the isoprenoid emissions became stable for each PPFD and leaf temperature. The air was drawn into the adsorbent tubes from the sampling port by a pump (210 Pocket pump, SKC, USA) for $10 \mathrm{~min}$ at a flow rate of $130 \mu \mathrm{mol} \mathrm{s}^{-1}$. The PPFD and temperature changing experiments were conducted three times, each time using different leaves.

\section{Isoprenoid analyses and data treatment}

Isoprenoids collected in adsorbent tubes were identified and quantified with gas chromatography-mass spectrometry (GC-MS; QP5050A, Shimadzu, Japan). The samples underwent two-stage thermal desorption (Turbo Matrix ATD-40, Perkin-Elmer, USA) and compound separation was achieved using an SPB-5 capillary column $(60 \mathrm{~m} \times 25 \mathrm{~mm}, 1 \mu \mathrm{m}$ film thickness, Supelco, USA). $\mathrm{GC}$ analytical procedures and parameters are described in detail elsewhere (Tani et al., 2002). The emission rates were determined both on the leaf area and dry weight bases.

To determine if isoprenoids were accumulated in leaves of $Q$. phillyraeoides, discs $\left(85 \mathrm{~mm}^{2}\right)$ were excised from the leaves at noon and isoprenoids in the leaf discs were extracted with $1 \mathrm{~mL}$ methanol. One- $\mu \mathrm{L}$ aliquots were analyzed with the GC-MS.

PTR-MS has been described in detail elsewhere (Lindinger et al., 1998; Hewitt et al., 2003). The drift tube $\mathrm{E} / \mathrm{N}$ (where $\mathrm{E}$ is the electric field strength and $\mathrm{N}$ is the buffer gas number density in the drift tube) was kept at $130 \mathrm{Td}$ by maintaining the drift tube voltage, temperature, and pressure at $520 \mathrm{~V}, 50^{\circ} \mathrm{C}$, and $2.0 \mathrm{mbar}$, respectively. Standardized count per seconds (SCPS) of masses originating from isoprene and monoterpenes were calculated from PTR-MS signals minus the background signals and drift tube pressures (Tani et al., 2003). As large amounts of monoterpenes were detected with GC-MS analysis, total SPCS of masses 81 and 137 were considered. The total SPCS is not affected by humidity and therefore needs no correction for humidity (Tani et al., 2004). Since a linear regression for 4 to 5 data sets was observed between the total monoterpene concentration determined with GCMS and total SCPS of masses 81 and 137, the monoterpene concentration during the PTR-MS measurements was determined from the SCPS using the regression equation. Before conducting the measurements, the background SPCS of masses $81+137$ in an empty cuvette was determined under different PPFD and temperature conditions, and these data were subtracted from the SPCS obtained during the emission measurements.

Isoprene emission model

Measured monoterpene emission rates for each PPFD and leaf temperature were normalized to basal emission rates under standard conditions of $30^{\circ} \mathrm{C}$ and $1,000 \mu \mathrm{mol} \mathrm{m}^{-2} \mathrm{~s}^{-1}$ PPFD using the 


\section{OKUMURA ET AL.}

G93 isoprene algorithm (Guenther et al., 1993). The G93 algorithm describes the PPFD and temperature dependence of isoprene emissions as

$$
M_{m}=M_{s} C_{L} C_{T}
$$

where $M_{m}$ is the isoprene emission rate at any temperature $T(\mathrm{~K})$, and light intensity $L$ (PPFD, $\mu$ mol $\left.\mathrm{m}^{-2} \mathrm{~s}^{-1}\right)$ and $M_{s}$ is the basal emission rate at a standard temperature $T_{s}(303 \mathrm{~K})$ and a standard PPFD $\left(1,000 \mu \mathrm{mol} \mathrm{m}^{-2} \mathrm{~s}^{-1}\right) . \quad C_{L}$ and $C_{T}$ are correction terms for light and temperature, respectively, defined as

$$
\begin{aligned}
C_{L} & =\frac{a C_{L 1} L}{\sqrt{1+a^{2} L^{2}}} \\
C_{T} & =\frac{\exp \left\{C_{T 1}\left(T-T_{S}\right) /\left(R T_{S} T\right)\right\}}{1+\exp \left\{C_{T 2}\left(T-T_{M}\right) /\left(R T_{S} T\right)\right\}}
\end{aligned}
$$

where $R$ is the gas constant $\left(=8.314 \mathrm{~J} \mathrm{~K}^{-1} \mathrm{~mol}^{-1}\right)$, and $\alpha$ ( $=0.0027$ units), $C_{L 1}$ (=1.066 units), $C_{T 1}$ $\left(=95,000 \mathrm{~J} \mathrm{~mol}^{-1}\right), C_{T 2}\left(=230,000 \mathrm{~J} \mathrm{~mol}^{-1}\right)$, and $T_{M}(=314 \mathrm{~K})$ are empirically derived constants.

\section{RESULTS}

\section{Isoprenoid emission composition of Q. phillyraeoides}

The emission composition of $Q$. phillyraeoides from three source habitats (Yakushima, Wakayama, and Shizuoka) is given in Fig. 1. The emissions in all the trees were dominated by sabinene (34.5 $\pm 5.2 \%), \alpha$-pinene (39.4 $\pm 3.8 \%)$, and $\beta$-pinene $(20.4 \pm 2.3 \%)$; their sum accounted for more than $90 \%$ of the total. The minor compounds were isoprene, $\alpha$-thujene, camphene, myrcene, limonene, $\beta$-phellandrene, $\gamma$-terpinene, and linalool. No obvious difference of composition between source habitats was observed.

Monoterpene emission responses to light and leaf temperature

Figure 2 shows responses of total monoterpene emission rates $\left(M_{m}\right)$ and net assimilation rate (A) of $Q$. phillyraeoides to light and leaf temperature. When PPFD was controlled at 1,000 $\mu \mathrm{mol}$ $\mathrm{m}^{-2} \mathrm{~s}^{-1}, M_{m}$ and $A$ increased gradually, and then reached a steady state (upper panel in Fig. 2). It took $2 \mathrm{~h}$ for $M_{m}$ to become constant. When PPFD was changed to lower levels but leaf temperature was kept constant at $25^{\circ} \mathrm{C}, M_{m}$ started to decrease and reached a steady state within $20 \mathrm{~min}$. This response of $M_{m}$ to PPFD was similar to that of isoprene emission from isoprene emitters, and com-

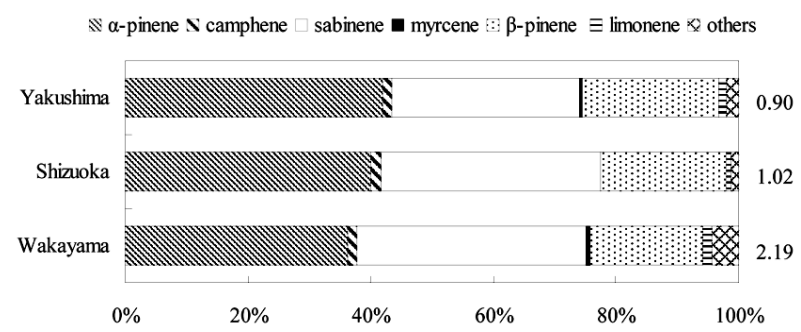

Fig. 1 Emission composition of $Q$. phillyraeoides from three source habitats (Yakushima, Wakayama, and Shizuoka). Measurements were conducted at $500^{-} 800 \mu \mathrm{mol} \mathrm{m}^{-2} \mathrm{~s}^{-1}$ PPFD and $28^{-}-32^{\circ} \mathrm{C}$ leaf temperature. The values on right side are the average emission rates on leaf area basis $\left(\mathrm{nmol} \mathrm{m}^{-2} \mathrm{~s}^{-1}\right)$. Percentages of the monoterpene compositions are averages of five measurements using different saplings. Relative standard deviations of the percentages of sabinene and $\alpha$ - and $\beta$-pinenes are less than $10 \%$. 
pletely different from that of monoterpene emission from plants with storage organs. No detectable amounts of monoterpenes $\left(<0.3 \mu \mathrm{g} \mathrm{g}^{-1} \mathrm{DW}\right)$ were found in the leaf extracts from any of the three source habitats, suggesting that $Q$. phillyraeoides has no storage organs for monoterpenes.

In response to changing leaf temperature, $M_{m}$ increased with an increase in leaf temperature (lower panel in Fig. 2). Maximum $M_{m}$ was $3.51 \mathrm{nmol} \mathrm{m}^{-2} \mathrm{~s}^{-1}$ at $37.5^{\circ} \mathrm{C}$ leaf temperature, which was three times as much as $M_{m}$ at $25^{\circ} \mathrm{C}$. Monoterpene emission responses of the other two leaves were similar to this result.

\section{Applying the isoprene algorithm for predicting monoterpene emission}

The $M_{m}$ values for each PPFD and leaf temperature shown in Fig. 2 were normalized to basal emission rates $\left(M_{s}\right)$ under standard conditions of $30^{\circ} \mathrm{C}$ and $1,000 \mu \mathrm{mol} \mathrm{m}^{-2} \mathrm{~s}^{-1}$ PPFD using the G93 isoprene algorithm (Guenther et al., 1993). $M_{S}$ values of the two leaves were determined as a slope of the regression line of $M_{m}$ obtained under stable conditions against light factor $\left(C_{L}\right) \times$ leaf temperature factor $\left(C_{T}\right)$. The $M_{m}$ value was highly correlated with $C_{L} \times C_{T}$ in both the leaves $(r>0.99)$ and the calculated $M_{S}$ values for upper and lower panels in Fig. 2 were 1.44 and $2.10 \mathrm{nmol} \mathrm{m}^{-2} \mathrm{~s}^{-1}$, respectively. To compare the measured $M_{m}$ value with the estimated value $\left(M_{e}\right)$, both the values are plotted together in Fig. 3. $M_{e}$ values were in close agreement with the corresponding $M_{m}$ values, suggesting that the G93 isoprene algorithm successfully estimates monoterpene emission from $Q$. phillyraeoides.

Basal emission rates of $Q$. phillyraeoides

Isoprenoid emission rates of the 15 trees measured using the branch enclosure method were
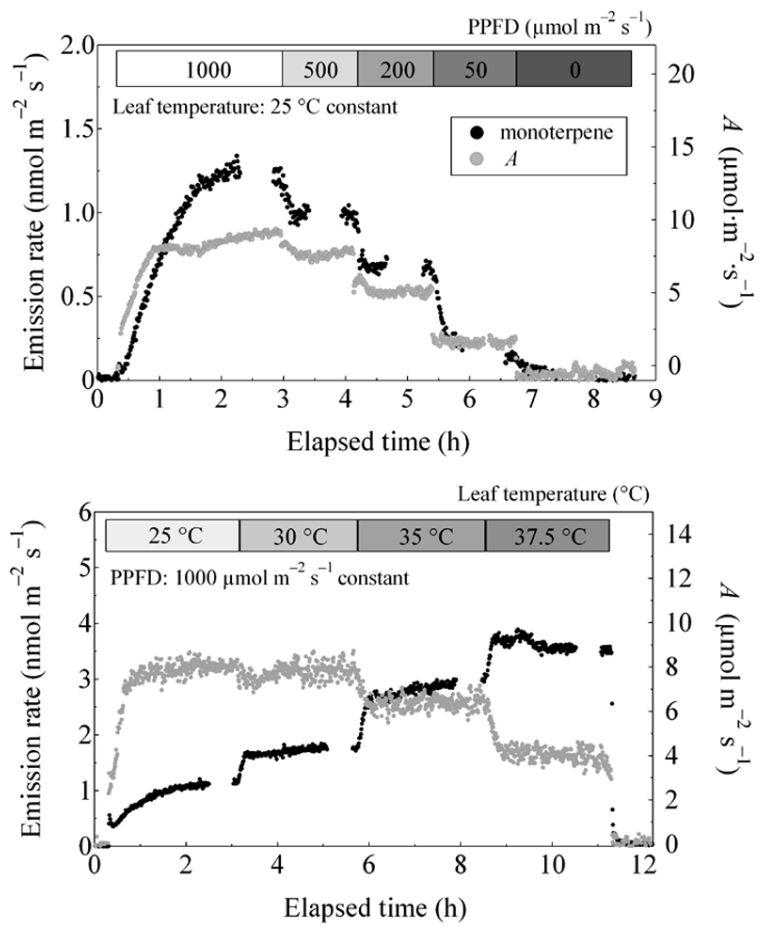

Fig. 2 Responses of total monoterpene emission rate and net assimilation rate $(A)$ of $Q$. phillyraeoides to light and leaf temperature. Upper and lower panels show the responses to light intensity and leaf temperature, respectively. PPFD and leaf temperature varied from 0 to $1,000 \mu \mathrm{mol} \mathrm{m}^{-2} \mathrm{~s}^{-1}$ and from 25 to $37.5^{\circ} \mathrm{C}$, respectively. The periods without monoterpene emission data were caused by adsorbent samplings for GC-MS analysis. The end of the Teflon tube exiting from the leaf cuvette was removed from the PTR-MS inlet and connected to the adsorbent tube. The samplings were initiated after the monoterpene emissions became stable. 


\section{OKUMURA ET AL.}

normalized to $M_{S}$ (Fig. 4). $M_{S}$ on the leaf area basis in the three habitats (Yakushima, Wakayama, and Shizuoka) ranged between $0.07-3.10,0.89-6.30$, and $0.21-2.74 \mathrm{nmol} \mathrm{m}^{-2} \mathrm{~s}^{-1}$, respectively. $M_{S}$ on the leaf dry weight basis in the three habitats ranged between $0.22-6.56,2.44-14.3$, and $0.51^{-}$ $5.76 \mu \mathrm{g} \mathrm{g}^{-1} \mathrm{~h}^{-1}$, respectively. As the tree-to-tree differences of emissions from identical source habitats were large, the $M_{S}$ values were not significantly different between the three habitats.

\section{DISCUSSION}

\section{Monoterpene emission and composition of $Q$. phillyraeoides}

Loreto et al. (2002) reported that $Q$. phillyraeoides native to China did not emit a detectable amount of monoterpenes. On the other hand, we have detected certain amounts of monoterpene emissions from $Q$. phillyraeoides native to Japan. We used 15 saplings from three different habitats in Japan and confirmed that all of them emitted monoterpenes. Although the genetic variation between Chinese and Japanese $Q$. phillyraeoides may be a cause of this discrepancy, further research is required to clarify the detailed geographical variation of monoterpene emissions from $Q$. phillyraeoides grown in China, Japan, and other countries in East Asia.

Several Mediterranean evergreen oak species like $Q$. ilex and Q. coccifera are strong monoterpene emitters (BEMA, 1997; Kesselmeier et al., 1996). The major monoterpenes emitted
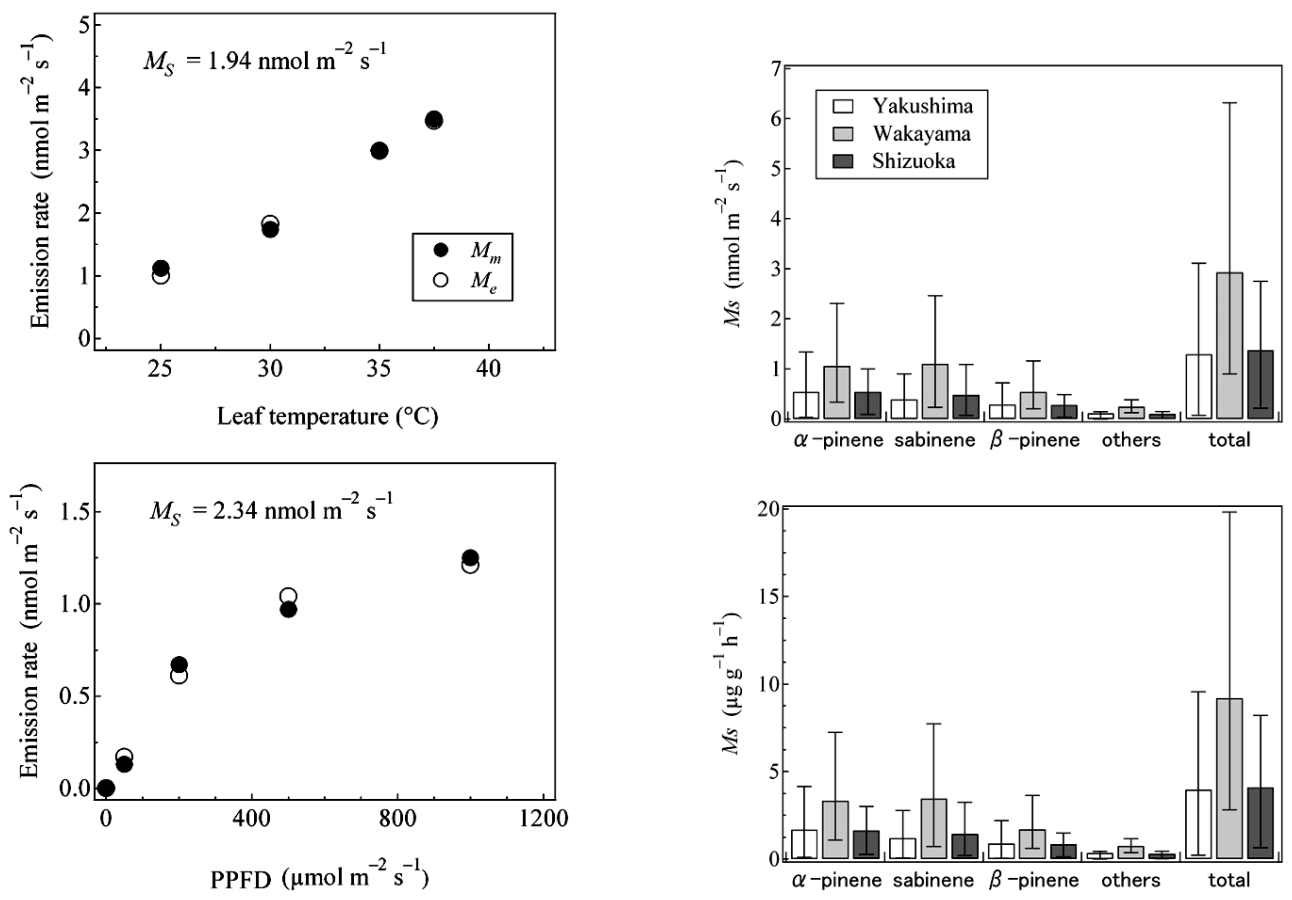

Fig. 3 Monoterpene emission rates measured in the experiments $\left(M_{m}\right)$ and estimated using the isoprene algorithm of Guenther et al. (1993) $\left(M_{e}\right)$. Basal emission rate $\left(M_{S}\right)$ of each of the leaves was determined as a slope of the regression line of $M_{m}$ against light factor $\left(C_{L}\right) \times$ leaf temperature factor $\left(C_{T}\right)$.

Fig. 4 Basal emission rates of $Q$. phillyraeoides from three source habitats. Error bars represent maximum and minimum values. 
by $Q$. ilex and $Q$. coccifera are $\alpha$ - and $\beta$-pinenes, sabinene, and myrcene. The minor compounds were $\alpha$-thujene, ocimene, $\beta$-phellandrene, $\gamma$-terpinene, and linalool (e. g., Csiky and Seufert, 1999). Monoterpene emission and composition of $Q$. phillyraeoides are similar to those of $Q$. ilex and $Q$. coccifera. The monoterpene emissions of $Q$. phillyraeoides were strongly affected by light intensity and leaf temperature, as in the case of $Q$. ilex. On the other hand, $M_{s}$ of $Q$. phillyraeoides was lower than those $\left(6^{-} 58 \mu \mathrm{g} \mathrm{g}^{-1} \mathrm{~h}^{-1}\right)$ of $Q$. ilex and Q. coccifera (Kesselmeier and Staudt, 1999 and references therein). As the emission capacity might be significantly lower in potted saplings than in field-grown trees (Csiky and Seufert, 1999), it might also be the case with the $M_{S}$ values obtained in our study.

Analogy between Q. phillyraeoides and Mediterranean monoterpene-emitting oak species

Q. phillyraeoides is a species for which the taxonomic classification is not entirely settled. For example, $Q$. phillyraeoides was classified into section Cerris based on morphological cladistic and chemo-taxonomic analyses (Manos et al., 1999). On the other hand, Flora of Japan (Iwatsuki et al., 2006) and Suzuki (1975) treated Q. phillyraeoides as subgenus Sclerophyllodrys and section Ilex, respectively.

Q. phillyraeoides is an evergreen oak species, and grows in poor soil, and dry and warm areas on the Pacific coast of Japan (Suzuki, 1975). Its leaf is smaller than those of any other Japanese Quercus spp. The acorn shell surface of $Q$. phillyraeoides is also squamate like the tree species classified in subgenus Quercus. Its habitat and morphologic features are very similar to those of the Mediterranean monoterpene-emitting oak species. Recent studies have suggested that the isoprenoid emissions by oak species are reliable taxonomical markers to distinguish subgenera or sections of Quercus (Loreto et al., 1998; Csiky and Seufert 1999; Loreto, 2002). Therefore, $Q$. phillyraeoides may be a species taxonomically close to European monoterpene-emitting oaks (e. g., Q. ilex).

\section{CONCLUSION}

We have identified the Japanese native evergreen oak species, Q. phillyraeoides, as a monoterpene emitter. Sabinene, and $\alpha$ - and $\beta$-pinenes were major compounds and accounted for more than $90 \%$ of the total monoterpene emissions. These emissions depend significantly on light intensity and leaf temperature. The G93 isoprene algorithm could successfully estimate monoterpene emission from $Q$. phillyraeoides. Q. phillyraeoides might be taxonomically close to European monoterpene-emitting oaks.

This study was partially supported by a Grant-in-Aid for Exploratory Research, 2007, No. 19651009, from the Japanese Ministry of Education, Culture, Sports, Science and Technology, and by Plant Research Grant, 2008, from the New Technology Development Foundation.

\section{REFERENCES}

BEMA. 1997. BEMA, A European commission project on biogenic emissions in the Mediterranean area. Atmospheric Environment 31: Suppl. 1-256.

Claeys, M., Wang, W., Ion, A. C., Kourtchev, I., Gelencser, A., Maenhaut, W. 2004. Formation of secondary organic aerosols from isoprene and its gas-phase oxidation products through reaction with hydrogen peroxide. Atmos. Environ. 38: 4093-4098.

Ciccioli, P., Fabozzi, C., Brancaleoni, E., Cecinato, A., Frattoni, M., Loreto, F., Kesselmeier, J., Schäfer, L., Bode, K., Torres, L., Fugit, J. L. 1997 . Use of the isoprene algorithm for predicting the monoterpene emission from the Mediterranean holm oak Quercus ilex L: performance and limits of this approach. J. Geophys. Res. 102: 23319-23328. 


\section{OKUMURA ET AL.}

Csiky, O., Seufert, G. 1999. Terpenoid emissions of Mediterranean oaks and their relation to taxonomy. Ecol. Appl. 9: 1138-1146.

Fall, R. 1999. Biogenic emissions of volatile organic compounds from higher plants, In "Reactive Hydrocarbons in the Atmosphere" (ed. by Hewitt, N.), Academic press, San Diego, p 41-96.

Fehsenfeld, F., Calvert, J., Goldan, R., Guenther, A. B., Hewitt, C. N., Lamb, B., Liu, S., Trainer, M., Westberg, H., Zimmerman, P. 1992. Emissions of volatile organic compounds from vegetation and the implications for atmospheric chemistry. Global Biochem. Cycles 6: 389-430.

Geron, C., Guenther, A., Greenberg, J., Loescher, W. H., Clark, D., Baker, B. 2002. Biogenic volatile organic compound emissions from a lowland tropical wet forest in Costa Rica. Atmos. Environ. 36: 37933802 .

Guenther, A., Zimmerman, P. R., Harley, P. C. 1993. Isoprene and monoterpene emission rate variability: model evaluations and sensitivity analysis. J. Geophys. Res. 98: 12609-12617.

Guenther, A., Hewitt, C. N., Erickson, D., Fall, R., Geron, C., Graedel, T., Harley, P., Klinger, L., Lerdau, M., Mckay, W. A., Pierce, T., Scholes, B., Steinbrecher, R., Tallamraju, R., Taylor, J., Zimmerman, P. 1995. A global-model of natural volatile organic compound emissions. J. Geophys. Res. 100(D5): 8873-8892.

Guenther, A. 2002. The contribution of reactive carbon emissions from vegetation to the carbon balance of terrestrial ecosystems. Chemosphere 49: 837-844.

Hewitt, C. N., Hayward, S., Tani, A. 2003. The application of proton transfer reaction-mass spectrometry (PTR-MS) to the monitoring and analysis of volatile organic compounds in the atmosphere. Journal of Environmental Monitoring 5: 1-7.

IPCC. 2001. Atmospheric chemistry and green house gases, In "IPCC Third Assessment Report - Climate Change 2001: The Scientific Basis" IPCC, Geneva, p 238-287.

Iwatsuki, K., Boufford, D. E., Ohba, H. 2006. Flora of Japan. Volume IIa. Kodansha, Tokyo, pp 455.

Kesselmeier, J., Schafer, L., Ciccioli, P., Brancaleoni, E., Cecinato, A., Frattoni, M., Foster, P., Jacob, V., Denis, J., Fugit, J. L., Dutaur, L., Torres, L. 1996. Emission of monoterpenes and isoprene from a Mediterranean oak species Quercus ilex L. measured within the BEMA (Biogenic Emissions in the Mediterranean Area) project. Atmos. Environ. 30: 1841-1850.

Kesselmeier, J., Staudt, M. 1999. Biogenic volatile organic compounds (VOC): An overview on emission, physiology and ecology. Journal of Atmospheric Chemistry 33: 23-88.

Klinger, L. F., Li, Q., Guenther, A. B., Greenberg, J. P., Baker, B., Bai, J. 2002. Assessment of volatile organic compound emissions from ecosystems of china. J. Geophys. Res. 107: ACH 16-1-ACH 16-21.

Lindinger, W., Hansel, A., Jordan, A. 1998. On-line monitoring of volatile organic compounds at pptv levels by means of proton-transfer-reaction mass spectrometry (PTR-MS) medical applications, food control and environmental research. International Journal of Mass Spectrometry 173: 191-241.

Loreto, F. 2002. Distribution of isoprenoid emitters in the Quercus genus around the world chemotaxonomical implications and evolutionary considerations based on the ecological function of the trait. Perspectives in Plant Ecology Evolution and Systematics 5: 185-192.

Loreto, F., Centritto, M., Baraldi, R., Rapparini, F., Liu, S. 2002. Emission of isoprenoids from natural vegetation in the Beijing region (Northern China). Plant Biosystems 136: 251-256.

Loreto, F., Ciccioli, P., Brancaleoni, E., Valentini, R., De Lillis, M., Csiky, O., Seufert, G. 1998. A hypothesis on the evolution of isoprenoid emission by oaks based on the correlation between emission type and Quercus taxonomy. Oecologia 115: 302-305.

Manos, P. S., Doyle, J. J., Nixon, K. C. 1999. Phylogeny, biogeography, and processes of molecular differentiation in Quercus subgenus Quercus (Fagaceae). Molecular Phylogenetics and Evolution 12: 333-349.

Okumura, M., Tani, A., Kominami, Y., Takanashi, S., Kosugi, Y., Miyama, T., Tohno, S. 2008. Isoprene emission characteristics of Quercus serrata in a deciduous broad-leaved forest. J. Agric. Meteorol. 64: 4960.

Peñuelas, J., Llusià, J. 1999. Seasonal emission of monoterpenes by the Mediterranean tree Quercus ilex in field conditions: relations with photosynthetic rates, temperature and volatility. Physiol. Plant. 105: 641647.

Staudt, M., Seufert, G. 1995. Light-dependent emission of monoterpenes by holm oak (Quercus ilex L.). Naturwissenschaften 82: 89-92.

Suzuki, T. 1975. Warm-temperate forests. In "Studies in Conservation of Natural Terrestrial Ecosystems in Japan. Part 1: Vegetation and its Conservation. JIBP Synthesis” (ed. by Numata, M., Yoshioka, K., Kato, M.), Vol. 8. University of Tokyo press, Tokyo, p 34-38. 


\section{MONOTERPENE EMISSIONS FROM OAK}

Tani, A., Kawawata, Y. 2008. Isoprene emission from native deciduous Quercus spp. in Japan. Atmos. Environ. 42: 4540-4550.

Tani, A., Fushimi, K. 2005. Effects of temperature and light intensity on isoprene emission of Edgeworthia chrysantha. (in Japanese with English summary) J. Agric. Meteorol. 61: 113-122.

Tani, A., Hayward, S., Hansel, A., Hewitt, C. N. 2004. Effect of water vapour pressure on monoterpene measurements using proton transfer reaction-mass spectrometry (PTR-MS). International Journal of Mass Spectrometry 239: 161-169.

Tani, A., Hayward, S., Hewitt, C. N. 2003. Measurement of monoterpenes and related compounds by proton transfer reaction-mass spectrometry (PTR-MS). International Journal of Mass Spectrometry 223-224: 561-578.

Tani, A., Nozoe, S., Aoki, M., Hewiit, C. N. 2002. Monoterpene fluxes measured above a Japanese red pine forest at Oshiba plateau, Japan. Atmos. Environ. 36: 3391-3402.

Yokouchi, Y., Ambe, Y. 1984. Factors affecting the emission of monoterpene from red pine (Pinus Densiflora). Plant Physiol. 75: 1009-1012. 